\title{
TENDÊNCIAS DO CONTROLE CLIMÁTICO OCEÂNICO SOB A VARIABILIDADE TEMPORAL DA PRECIPITAÇÃO NO NORDESTE DO BRASIL
}

\author{
NÓBREGA, Ranyére Silva - ranyere.nobrega@ufpe.br \\ Universidade Federal de Pernambuco \\ SANTIAGO, Gabriela Ayane Chagas Felipe - gabriela_ayane@hotmail.com \\ Universidade Federal de Pernambuco \\ SOARES, Deivide Benicio - deividebenicio@yahoo.com.br \\ Universidade Federal de Pernambuco
}

\begin{abstract}
RESUMO: Com significante diferença na distribuição espaço-temporal da chuva, prolongados períodos de deficiência hídrica, solos problemáticos e ausência de rios perenes, o sertão nordestino é a região mais vulnerável às mudanças climáticas no Brasil. Baseado em análise de dados climatológicos, este trabalho objetiva identificar tendências nas temperaturas da superfície do mar nos oceanos Atlântico Norte, Atlântico Sul, Pacífico Leste e Pacífico Central e a relação com a variabilidade temporal da precipitação em Pernambuco em períodos recentes. Foram utilizados três métodos para alcançar o objetivo proposto. Para evidenciar a relação entre os oceanos e as chuvas no NEB foi utilizado o Índice de Anomalia de Chuva. Na investigação de tendências nas TSM's foi utilizado o método de Mann-Kendall, sugerido pela World Meteorological Organization (WOM). Para evidenciar se há mudanças na precipitação atual foram utilizados os índices climáticos sugeridos pela Equipe de Especialista em Deteç̧ão, Monitoramento e Índices de Mudanças Climáticas. Os índices de mudanças climáticas indicaram que vem ocorrendo mudanças nos padrões de pluviometria, com tendência de aumento no volume de chuva (com exceção do litoral leste) e distribuição sazonal mais concentrada. A análise estatística das TSM's sobre o oceano Pacífico e Atlântico permitiu observar que há tendência de aquecimento e que, quando analisados isoladamente a ocorrência de anomalias positivas sobre o Pacífico leste (EI Niño) e anomalias negativas sobre o Atlântico Sul (dipolo positivo), as secas são mais severas, baseado na análise do índice de anomalia de chuva. Também baseado no IAC, conclui-se que ambos os eventos quando ocorrem isoladamente exercem influência na precipitação da região, no entanto, quando agem em conjunto percebesse que essa influência é mais acentuada, alterando o comportamento da circulação geral da atmosfera meridionalmente (célula de Hadley) e zonalmente (célula de Walker).
\end{abstract}

PALAVRAS-CHAVE: mudanças climáticas, impactos climáticos, desastres naturais.

TRENDS OF OCEANIC CLIMATE CONTROL UNDER TEMPORARY VARIABILITY OF RAINFALL IN NORTHEAST BRAZIL

ABSTRACT: With significant differences in spatial and temporal distribution of rainfall, prolonged periods of water stress, problematic soils and absence of perennial rivers, the Northeastern interior is the region most vulnerable to climate change in Brazil. Based on analysis of climate data, this study objective to identify trends in sea surface temperatures in the North Atlantic, South Atlantic, East Pacific and Central Pacific Oceans and the relation with the temporal variability of precipitation in Pernambuco in recent periods. Three methods were used to achieve the proposed objective. As evidence of the relationship between the oceans and the rain in NEB was used Rain Anomaly Index. Research trends in TSM's the Mann-Kendall method, suggested by the World Meteorological Organization (WOM). To evidence if there are changes in the current precipitation were used climate indices suggested by the Expert Team on Detection, Monitoring and Climate Change Indices. The climate change indices indicated that has been occurring changes in rainfall patterns, with a tendency of increase in the volume of rain (except for the east coast) and more concentrated seasonal distribution. Statistical analysis of TSM's on the Pacific and Atlantic 
allowed to observe that there is warming trend and that when alone analyzed the occurrence of positive anomalies over the eastern Pacific (EI Niño) and negative anomalies over the South Atlantic (positive dipole), the droughts are more severe, based on the analysis of rainfall anomaly index. Also based on the IAC, it is concluded that both events when they occur alone exert influence on rainfall in the region, however, when they act together to realize that this influence is more pronounced, changing the behavior of the general circulation of the atmosphere meridionaly (Hadley cell ) and zonally (Walker cell).

KEYWORDS: climate change, climate impacts, natural disasters.

\section{INTRODUÇÃO}

As regiões semiáridas são uma das mais vulneráveis às mudanças climáticas porque em condições de aumento de temperatura e mudanças na precipitação podem se tornar regiões áridas, implicando em alterações não só climáticas, mas fitogeográficas, práticas econômicas e sociais. Na América do Sul existem três grandes áreas semiáridas: a região de Guajira, na Venezuela e Colômbia, a diagonal seca do Cone Sul ao longo de Argentina, Chile e Equador, e a região do Nordeste do Brasil, caracterizada por temperaturas médias anuais elevadas e alta variabilidade espaço temporal da precipitação, com predomínio fitogeográfico da caatinga.

$A b$ 'Saber (2006) ventila sobre os atributos que apresentam similaridade nas regiões semiáridas, como baixos níveis de umidade, escassez de chuvas, irregularidade no ritmo da precipitação ao longo dos anos, prolongados períodos de deficiência hídrica, solos problemáticos e ausência de rios perenes. No Nordeste brasileiro (NEB) o volume anual de precipitação é relativamente elevado, comparada com as outras regiões semiáridas, variando entre $400 \mathrm{~mm}$ a $800 \mathrm{~mm}$, porém as concentrações destas chuvas são entre dois a quatro meses, sobre solo cristalino, em sua maior parte, de difícil infiltração, com alto teor de cloreto de sódio, e alta taxa de evaporação.

De um modo geral, o controle climático oceânico exerce influência primordial nos níveis pluviométricos do NEB. Então, surgem questionamentos sobre o comportamento da climatologia da TSM do Atlântico e do Pacífico leste em um período onde se procura evidências de mudanças climáticas globais e os impactos que podem ser potencializados ou até mesmo surgir.

Um aspecto que torna o NEB bastante vulnerável as mudanças climáticas é ser a região semiárida mais povoada do mundo, graças a um histórico avanço migratório oriundo das terras úmidas do litoral leste do Brasil em direção ao interior continental nordestino, também conhecido por sertão nordestino.

O sertão nordestino possui uma área de aproximadamente $700.000 \mathrm{~km}^{2}$, onde vive mais de 24 milhões de habitantes (IBGE, 2010). É a região mais pobre do Brasil, com considerável parte da população residindo no meio rural, praticando agricultura familiar. Pode-se afirmar que a região está sob intervenção pública, na qual o planejamento estatal determina projetos e incentivos econômicos de alcance desigual. Todavia, não é possível deixar de apontar também, como Ab'Saber (2006) destaca, o caráter híbrido de seu perfil socioeconômico atual, que combina arcaísmos generalizados com importantes elementos pontuais de modernização, tais como uma razoável hierarquização urbana, um bom sistema de rodovias asfaltadas que garante as ligações intra e interregionais, e uma rede de açudes, com diferentes possibilidades de fornecimento de água para áreas irrigáveis de planícies de inundação (vazantes), além a extraordinária área de irrigação de Petrolina (Pernambuco) e Juazeiro (Bahia), no médio vale inferior do São Francisco.

Em se tratando de mudanças climáticas globais, o relatório do IPCC (2013) aponta que o NEB é um hot spot, e com grande possibilidade de ser o maior do Brasil. Quando se fala de vulnerabilidade e mudanças climáticas muitas vezes são utilizados os modelos de previsão de mudanças climáticas para projetar cenários. Marengo (2008) analisou os diversos 
modelos e as previsões de precipitação e temperatura para o Brasil. O autor observou que sobre o NEB há considerável divergência entre os modelos, com previsões de diminuição a aumento de chuva. Todavia, são unânimes ao identificar mudanças nas temperaturas, com aumento dos valores, o que implicaria em mudanças no balanço hídrico da região.

A variabilidade climática e os seus impactos sempre estiveram presentes na história da humanidade e nos últimos anos vêm deixando o mundo em alerta e desafiando os pesquisadores a desvendar as rápidas e severas mudanças do clima no mundo (KOBIYAMA et al., 2011). Uma discussão quase que unânime é que a intensidade desses eventos serão potencializadas. Soma-se a este fato, a dificuldade de gerenciamento de planos para a adaptação e a atenuação de seus efeitos, devido à impossibilidade de prevê-los com exatidão.

Como os modelos climáticos não convergem em termos de projeções pluviométricas para o NEB, enxerga-se que é importante identificar se há sinais de mudanças nos padrões climáticos e qual a implicação na região.

A variabilidade da precipitação na região é, em diversos estudos, relacionada ao fenômeno El Niño (ENOS), baseados na hipótese de que alguns anos de El Niño fortes ou moderados a capital do estado do Ceará enfrentou secas severas (KANE, 1997). Sobre o oceano, o ENOS é caracterizado pela ocorrência de temperatura da superfície do mar (TSM) no Pacífico equatorial central e leste anomalamente positivas (El Niño) e negativas (La Niña). Há uma conexão dinâmica entre este componente e à Oscilação Sul, que se reflete como uma gangorra barométrica com centros de ação na Indonésia e no Pacífico sudeste.

Segundo Andreoli et al. (2004) a relação entre El Niño e as secas no NEB não é unívoca, uma vez que Kane (1997) mostrou que dos 46 El Niño (fortes e moderados) do período de 1849-1992, somente 21 (45\%) estiveram associados a secas severas em Fortaleza. Outros pesquisadores também destacam a relação entre a precipitação e o Atlântico Tropical em estudos observacionais e estatísticos, como as realizadas por Hastenrath e Heller (1977), e também com simulações numéricas por Moura e Shukla (1981), Servain (1991), Nobre e Shukla (1996). Mais recentemente, Kayano e Capistrano (2013) evidenciaram um padrão de anomalias da TSM sobre o oceano Atlântico tropical, comumente chamado de padrão de Dipolo do Atlântico, e que este padrão está associado a mudanças nos valores de precipitação sobre a região Nordeste e Norte do Brasil.

Na última década foi registrada a ocorrência de eventos El Niño nos anos 2002 a 2007 e no biênio 2009-2010 (dados do Instituto Nacional de Meteorologia do Brasil), o que não refletiu em períodos secos sobre o NEB, seja por conta da intensidade do evento ou porque o dipolo do Atlântico exerceu maior influência, o que já indica a importância de se analisar as anomalias tanto no Oceano Pacífico quanto no Atlântico (XAVIER e XAVIER, 2007).

De fato, o clima do Nordeste do Brasil é marcado por uma reconhecida variabilidade temporal da precipitação, que se expressa em diversas escalas. Da mesma forma, ocorre uma substantiva irregularidade espacial das chuvas, dentro do mesmo intervalo temporal, em virtude da atuação de sistemas meteorológicos de diferente abrangência sobre a região. Neste contexto regional, onde se concentra ainda uma sociedade marcadamente agrária, com o uso práticas tradicionais de cultivo e pecuária, o clima e seus ritmos são fundamentais para a compreensão da organização do espaço, seja do ponto de vista da distribuição dos atributos físicos da paisagem; solos, fitofisionomias, padrões de drenagem etc., como também das atividades econômicas, predominantemente dependentes dos aportes hídricos e disponibilidade de solos. Assim sendo, um estudo dos componentes da variabilidade climática da região permite aprofundar o conhecimento sobre como uma variável do sistema climático pode se refletir sobre a vulnerabilidade das organizações espaciais agrárias e naturais, desencadeando processos físicos e sociais que interfiram diretamente sobre a distribuição dos padrões de uso da terra e dinâmica superficial da região (ritmo de secas severas, inundações, enchentes, relâmpago etc. Este tipo de contribuição representa um avanço para a compreensão das interações entre o clima e a dinâmica espacial, e portanto para a própria Climatologia Geográfica, uma vez que ao tratar 
os aspectos da variabilidade climática a partir de um de seus componentes controladores, passa a oferecer explicações mais robustas, do ponto de vista empírico, sobre a relação entre os eventos climáticos de diversas magnitudes, e sua variação espaço-temporal, sobre a dinâmica dos os diversos arranjos sócio naturais que compõem os mosaicos regionais do semiárido do NEB.

Diante do exposto, o objetivo deste trabalho é identificar tendências nas temperaturas da superfície do mar nos oceanos Atlântico Norte, Atlântico Sul, Pacífico Leste e Pacífico Central e a relação com a variabilidade temporal da precipitação em Pernambuco, traçando perfis de vulnerabilidade frente as mudanças climáticas para a região.

O artigo está dividido em uma breve revisão bibliográfica sobre variabilidade da precipitação no Nordeste do Brasil, depois é apresentada a metodologia proposta para investigação desta variabilidade e se há sinais de mudanças climáticas para, por fim, discutir sobre as vulnerabilidades da região frente as mudanças climáticas.

\section{O fenômeno EI Niño e as chuvas no Nordeste Brasileiro}

Segundo Aragão (1998) o El Niño e a Oscilação do Sul (OS) são um fenômeno de escala global resultante da interação oceano-atmosfera, conhecido como ENOS. A definição mais geral é que o El Niño é resultante de anomalias positivas nos valores de TSM do Oceano Pacífico.

Este aquecimento se torna acima da média histórica, desenvolvendo uma anomalia positiva nos valores de temperatura da superfície do mar com grandes efeitos sobre o clima global. Na faixa equatorial a convecção se desloca para o leste, alterando o posicionamento da Célula de Walker.

Em condições normais, o ramo ascendente da Célula de Walker que é favorável à formação de nuvens convectivas com grande desenvolvimento vertical ocorre sobre o Pacífico Oeste-Equatorial, onde as águas são mais quentes, consequentemente acompanhadas de pressões atmosféricas mais baixas. O contrário ocorre sobre a região do Pacífico Leste, próximo à costa Ocidental da América do Sul, onde se pode observar águas mais frias e pressões atmosféricas mais altas, com isso há a formação do ramo subsidente da Célula, inibindo a precipitação. Quando se configura o fenômeno El Niño ocorre o deslocamento da Célula para o Pacífico Leste devido ao aquecimento anômalo da superfície do mar, favorecendo subsidência de ar sobre a bacia centro-oeste e sobre o Atlântico Equatorial, incluindo a Amazônia Oriental e o Nordeste do Brasil, o que explicaria episódios de seca nessa região.

Já a Oscilação do Sul é a variação anômala da pressão atmosférica tropical, sendo uma resposta aérea ao El Niño, associada com a mudança na circulação geral da Atmosfera. Segundo Klauer (2000) em anos de El Niño, a pressão tende a valores mais baixos no Pacífico e aumenta no restante da região tropical. $O$ índice (ou oscilação, a depender do autor) é definido como a diferença entre os desvios normalizados da pressão na superfície entre as regiões do Tahiti, no Pacífico central-sul e em Darwin, ao norte da Austrália.

Os ventos alísios sopram de NE e SE conhecidos como célula de Hadley. Um fluxo é formado de leste para oeste na área do Pacífico equatorial, varrendo as águas superficiais, dando lugar às águas profundas para aflorarem a superfície. Este mecanismo é chamado de ressurgência, próximo à costa oeste da América do sul. Na presença do El Niño, a intensidade dos ventos alísios diminui chegando a certo momento, a mudar de sentido, ou seja, de oeste para leste. Sem a força dos alísios, o acumulo de água aquecida no lado oeste do Pacífico espalha-se pelo Oceano Pacífico Equatorial central, chegando até o litoral Peruano tornando a termoclina (variação brusca de temperatura em uma determinada profundidade do mar ou em ambientes de água doce) da região mais profunda (BEZERRA e CAVALCANTI, 2008).

O fenômeno apresenta diferentes intensidades de anomalias na temperatura e também espacialmente, de maneira que Quinn et al. (1978) introduziram quatro categorias de EI 
Nino (forte, moderado, fraco, e muito fraco). Temporalmente o padrão observado é que episódio começa a se desenvolver em meados de um ano, por volta de novembro, atinge sua máxima intensidade no final do mesmo ano e dissipa-se em meados do ano seguinte.

Marengo et al. (1993) observaram que durante anos de El Niño a ZCIT encontra-se anomalamente mais ao norte de sua posição normal, assim os ventos alísios de SE e NE são mais fracos, reduzindo a umidade que penetra o NEB.

No entanto, Melo (1999) questionou se o El Niño é o responsável por toda a série de secas ocorridas no Brasil desde o período colonial, e o questionamento veio concomitantemente com o trabalho de Aragão (1998) que com base em séries e relatos históricos procurou relacionar os eventos em diversas intensidades e as secas no NEB. Melo (1999) descreveu que Aragão (1998) relatou 28 anos secos entre 1914 e 1997, relacionados com o El Niño e nem todos de forte intensidade (6 fortes, 7 moderados e 10 fracos). Então, supõe-se que o fenômeno não é sempre sinônimo de seca.

\section{O dipolo do Atlântico e as chuvas no Nordeste Brasileiro}

O Dipolo do Atlântico é o fenômeno oceano/atmosférico identificado como uma mudança anômala na temperatura da superfície água do mar no Oceano Atlântico Tropical, ou seja, quando as águas do Atlântico Tropical Norte estão mais quentes e as águas do Atlântico Equatorial e Tropical Sul estão mais frias existem movimentos descendentes transportando ar frio e seco dos altos níveis da atmosfera sobre a região setentrional, central e sertão do Nordeste inibindo a formação de nuvens e diminuindo a precipitação (Fase Positiva do Dipolo), podendo causar secas. Por outro lado, quando as águas do Atlântico Tropical Norte estão mais frias e as águas do Atlântico Tropical Sul estão mais quentes existem aumento nos movimentos ascendentes sobre estas regiões, intensificando a formação de nuvens e aumentando os índices pluviométricos (Fase Negativa do Dipolo) (HASTENRATH e HELLER, 1977; MOURA e SHUKLA, 1981; ARAGÃO, 1998).

Tal padrão de anomalias de TSM possibilita a ocorrência de gradientes meridionais de anomalias de TSM, os quais influenciam bastante na posição latitudinal da ZCIT, alterando assim a distribuição sazonal de precipitação pluviométrica sobre o Atlântico Equatorial, parte norte do Nordeste do Brasil, até a parte central da Amazônia (NOBRE e SHUKLA, 1996). Nos anos em que as TSM sobre o Atlântico Tropical Sul (entre a linha do equador e $15^{\circ} \mathrm{S}$ ) estão mais altas do que a média de longo período durante março-abril-maio (MAM) e o Atlântico Tropical Norte (entre $5^{\circ} \mathrm{N}$ e $20^{\circ} \mathrm{N}$ ) está menos aquecido do que a média, há formação de um gradiente meridional de anomalias de TSM no sentido de norte para sul. Nessa situação observa-se no mesmo período uma pressão ao nível do mar (PNM) mais baixa do que a média sobre o Atlântico Sul e mais alta do que a média sobre o Atlântico Norte, os alísios de sudeste mais fracos do que a média e os alísios de nordeste mais intensos do que a média, o eixo de baixa pressão à superfície e confluência dos ventos alísios deslocados mais para sul, relativamente ao seu posicionamento médio, e totais pluviométricos acima da média sobre o norte do Nordeste (HASTENRATH e HELLER, 1977).

Quando o dipolo do Atlântico está na fase negativa (presença de anomalias negativa no Atlântico norte e positiva no Atlântico sul), há o favorecimento de precipitação acima da média sobre o NEB, do contrário, em sua fase positiva, há o favorecimento de precipitação abaixo da média (ANDREOLI e KAYANO, 2007).

\section{Vulnerabilidades frente as Mudanças Climáticas}

O Nordeste Brasileiro é uma região vulnerável as mudanças climáticas por características fitogeográficas, sócias e econômicas. Estas características são variáveis no espaço, mas destaca-se a alta vulnerabilidade do sertão nordestino. Continuando a utilizar o estado de Pernambuco como referência, os resultados anteriores indicam, sem uso de modelos climáticos, que há evidências de alterações na distribuição e intensidade da 
precipitação. Somado a isso, os modelos climáticos do IPCC apontam para aumento de temperaturas entre $1,5^{\circ} \mathrm{C}$ a $3,0^{\circ} \mathrm{C}$ para a região, já sobre a precipitação não há consenso ou mesmo, maior prevalência nos resultados, sendo mais inconclusivos.

A escassez de recursos hídricos e episódios de eventos de seca vem afetando durante séculos a prática agrícola no sertão, que como consequência produz perdas agrícolas, má nutrição, mortes humanas, perdas pecuárias e um processo de migração (MARENGO, 2008; ANDRADE, 2005; GOMES, 2001).

É notório dizer que as secas no semiárido são episódios naturais, não excepcionais. Pesquisas atuais e de outrora evidenciam a já existente deficiência hídrica da região, porém, estudos com direcionamentos para cenários futuros apontam para aumento dos eventos extremos de seca na região, não somente pela diminuição da chuva, mas também pelo aumento da evapotranspiração e mudança na distribuição das chuvas (MARGULIS e DUBEUX, 2010; MARENGO et al., 2009). De certo modo, estes estudos convergem com os resultados aqui encontrados, o que se torna mais preocupante.

A pequena temporada de chuva, restrita de 2 a 4 meses já vem sofrendo alterações e com a tendência de aumento das TSM's sobre os oceanos Pacífico leste e Atlântico, ainda sofrerão mais alterações. Os impactos podem afetar mais de 2 milhões de famílias rurais que sobrevivem basicamente da agricultura familiar, que estão em condições de pobreza considerável (GUANZIROLI e CARDIM, 2000). A estimativa é que de $10 \%$ a $30 \%$ da população não-metropolitana e rural no NE é considerada pobre ou extremamente pobre, 0 maior percentual no Brasil (SILVEIRA et al., 2007).

Baixo uso de tecnologias apropriadas (por exemplo, falta de irrigação), insuficiente capacitação técnica e a contínua degradação da caatinga já afetam fortemente a produtividade agrícola (OBERMAIER, 2012; CARVALHO e EGLER, 2003). Acesso a serviços de saúde, renda familiar e taxas de escolaridade no sertão permanecem significativamente abaixo dos valores médios brasileiros, apesar de avanços consideráveis durante as últimas duas décadas (IBGE, 2010). Dessa forma, muitos agricultores continuam a depender de programas governamentais de transferência de renda ou fontes de emprego não-agrícolas para complementar seus parcos rendimentos (OBERMAIER, 2011; MALUF e BURLANDY, 2007; SILVA, 2006).

Em uma região onde a oligarquia estatal prevalece, somada a ausência de medidas de adaptação, as mudanças climáticas tornarão os produtos rurais do semiárido, ainda mais vulneráveis. Assad e Pinto (2008) mostraram que a que a produtividade da agricultura de subsistência pode sofrer importantes perdas na região, inclusive na produção de cultivos de subsistência (feijão, milho e mandioca), além da perda na produção leiteira. Os autores simularam cenários de produção agrícola, juntamente com os cenários do IPCC para mudanças climáticas. Para 2030, estimam perdas de produtividade para cultivos de subsistência podem ser da ordem de 5\%. Para 2050, as áreas agrícolas de baixo risco climático para feijão, arroz e milho são previstas de diminuir entre $10 \%$ a $15 \%$. Em uma região onde a produção agrícola já é limitada por condicionantes naturais (clima e solo), estas projeções possuem peso considerável.

Historicamente, durante os períodos de secas severas, há fluxos migratórios para os centros urbanos, nos séculos passados para regiões mais ricas do Brasil, como Sudeste e Sul, e mais recente para os grandes centros urbanos do NE. A migração traz consigo uma população rural não adaptada a vida urbana, principalmente em regiões metropolitanas e centros urbanos de porte médio. Alencar e Nóbrega (relato pessoal) investigam os fluxos migratórios da última seca em algumas localidades do sertão nordestino. Os autores constataram que os fluxos migratórios estão diminuindo de distância comparando com as secas anteriores, com a população procurando a Região Metropolitana do Recife, Petrolina, Serra Talhada, Caruaru. Ao chegar aos centros urbanos, a população é marginalizada, morando em áreas de riscos naturais e de saúde por falta de planejamento urbano, ocupando áreas irregulares. Tornando-as mais vulneráveis ainda. A intensificação das secas por consequência de mudanças climáticas tende a agravar este processo. 
Com a interação oceano-atmosfera evidenciando que há sinais de mudanças climáticas atuais e através dos cenários simulados para os anos vindouros, destacam-se três áreas de maior preocupação quanto as vulnerabilidades frente as mudanças climáticas no Nordeste, e que estão relacionadas entre sim. A saber, aumento no déficit hídrico, perdas na produtividade agrícola e processo migratório. Porém, é necessário mencionar que as mudanças climáticas não irão ser responsáveis pela gênese destes problemas, mas sim agravá-los, uma vez que a população nordestina já convive com estes impactos através da variabilidade climática, e com o advento das mudanças climáticas, a vulnerabilidade será potencializada, necessitando de ações mitigadoras para o agora e o futuro.

\section{MATERIAIS E MÉTODOS}

Para análise do objetivo proposto foram selecionados quatro municípios localizados no Estado de Pernambuco, Nordeste do Brasil representativos de aspectos fitogeográficos distintos. A localização dos municípios pode ser observada na Figura 1, enquanto as características climáticas podem ser observadas na Tabela 1.

Os índices mensais de anomalias de TSM que representam as variações de TSM para o Atlântico Norte (ATN), Atlântico Sul (ATS), El Niño 3 e El Niño 3.4 foram obtidos calculando a média das ATMS nos subsetores delimitados em: $2,5^{\circ} \mathrm{N}, 17,5^{\circ} \mathrm{N}, 72,5^{\circ} \mathrm{W}$ e $32,5^{\circ} \mathrm{W}$, para 0 ATN; em $12,5^{\circ} \mathrm{S}, 2,5^{\circ} \mathrm{N}, 37,5^{\circ} \mathrm{W}$ e $12,5^{\circ} \mathrm{E}$, para o ATS; $5^{\circ} \mathrm{N}, 5^{\circ} \mathrm{S}, 150^{\circ} \mathrm{W}$ e $90^{\circ} \mathrm{W}$ para 0 Niño 3 ; e $5^{\circ} \mathrm{N}, 5^{\circ} \mathrm{S}, 150^{\circ} \mathrm{W}$, e $120^{\circ} \mathrm{W}$ para o Niño 3.4 . As TSM foram obtidas do Goddard Institute for Space Studies (GISS) (HANSEN et al., 2001), para o período de 1950 a 2009. As áreas são as sugeridas por Enfield et al. (1999). A diferença entre os índices do ATN e ATS) descreve o gradiente de ATSM inter-hemisférico. No caso do Pacífico descreve as variações de TSM associadas ao ENOS.

Para evidenciar a relação entre os oceanos e as chuvas no NEB foi utilizado o Índice de Anomalia de Chuva - IAC (DA SILVA, GALVÍNCIO, NÓBREGA, 2011). O método de IAC utilizado pelos autores pode ser resumido nas seguintes equações:

$$
\begin{aligned}
& I A C=3\left[\frac{N-\bar{N}}{\bar{M}-\bar{N}}\right](\mathrm{a}) \\
& I A C=-3\left[\frac{N-\bar{N}}{\bar{X}-\bar{N}}\right] \text { (b) }
\end{aligned}
$$

Em que (a) é utilizado para anomalias positivas e (b) para anomalias negativas, em que: $\mathrm{N}=$ precipitação anual atual, ou seja, do ano que será gerado o IAC $(\mathrm{mm}) ; \mathrm{N}=$ precipitação média anual da série histórica $(\mathrm{mm}) ; \mathrm{M}=$ média das dez maiores precipitações anuais da série histórica $(\mathrm{mm}) ; \mathrm{X}=$ média das dez menores precipitações anuais da série histórica $(\mathrm{mm})$; e anomalias positivas são valores acima da média e negativas, abaixo da média. 


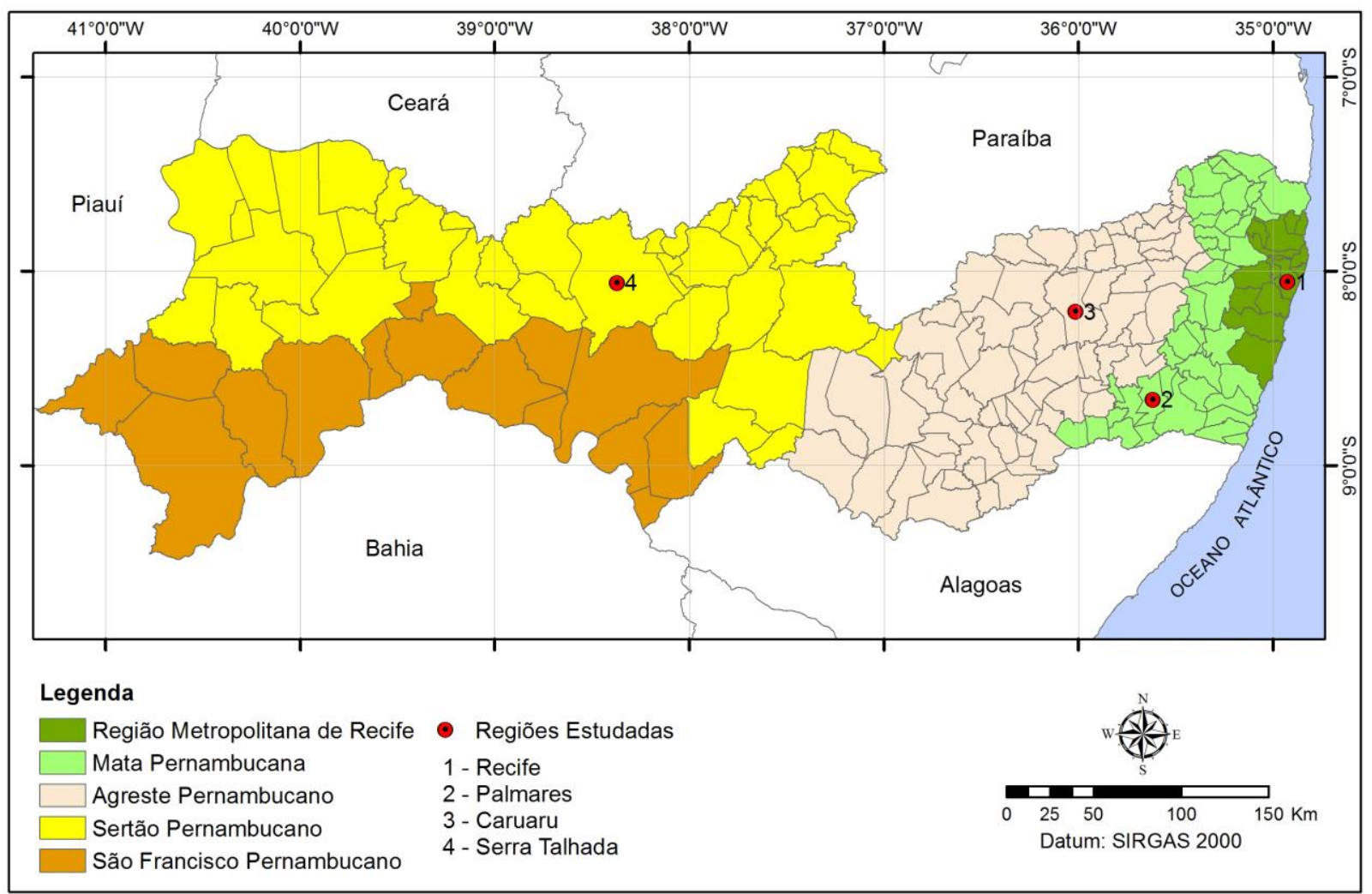

Figura 1 - Localização da área de estudo.

Tabela 1 - Climatologia de precipitação, evapotranspiração e temperatura dos municípios estudados.

\begin{tabular}{lccc}
\hline Município & $\begin{array}{c}\text { Precipitação Média } \\
\text { Anual }(\mathbf{m m})\end{array}$ & $\begin{array}{c}\text { Evapotranspiração } \\
\text { média Anual }(\mathbf{m m})\end{array}$ & $\begin{array}{c}\text { Temperatura } \\
\text { média anual }\left({ }^{\circ} \mathbf{C}\right)\end{array}$ \\
\hline Recife & 2457 & 1285 & 25,5 \\
Palmares & 1296 & 1157 & 23,2 \\
Caruaru & 765 & 1180 & 23,4 \\
Serra Talhada & 801 & 1535 & 25,8 \\
\hline
\end{tabular}

Outro índice que poderia ser utilizado é o de Palmer (Palmer Drought Severity Index PDSI), porém, para sua utilização são necessários dados de evapotranspiração, infiltração, escoamento superficial eventual e outros, expressando uma medida entre a diferença acumulada da precipitação normal e a precipitação necessária à evapotranspiração (HAVENS, 1969; STEILA, 1971; ALLEY, 1984; ALLEY, 1985; GUTTMAN, 1991). Já o IAC só necessita de dados de precipitação, se tornando mais simples de ser calculado e objetiva expressar o desvio da precipitação em relação à condição normal de diversas regiões passíveis de comparação.

$\mathrm{Na}$ investigação se há tendências nas TSM's foi utilizado o método de Mann-Kendall, sugerido pela World Meteorological Organization (WOM). Essa técnica, comumente conhecida como estatística Tau de Kendall, tem sido amplamente usada para testar: aleatoriedade contra tendência de séries temporais climatológicas (ZHANG et al., 2001).

Groppo et al. (2001) afirmam que este método é um teste estatístico não paramétrico, no qual, na hipótese da estabilidade de uma série temporal, os valores devem ser independentes e a distribuição de probabilidades deve permanecer sempre a mesma (série aleatória simples). Goossens e Berger (1986) afirmam que o método de Mann-Kendall é 
mais apropriado para analisar mudanças climáticas em séries climatológicas e permite também a detecção e localização aproximada do ponto inicial de determinada tendência.

Para evidenciar se há mudanças na precipitação atualmente foram utilizados os índices climáticos sugeridos pela Equipe de Especialista em Detecção, Monitoramento e Índices de Mudanças Climáticas (Expert Team on Climate Change Detection, Monitoring and Indices ETCCDMI) para os quatro municípios citados acima. Estes índices são utilizados para estudos de mudanças climáticas. Dos 27 índices climáticos sugeridos, 16 são referentes a temperatura e 11 referentes a precipitação. Aqui neste trabalho foram utilizados 8 índices de precipitação (Tabela 2). Diversos estudos vêm utilizando estes índices climáticos ao longo do globo. Para uma revisão mais detalhada sobre os índices e locais onde vem sendo aplicado, sugere-se a leitura de Santos (2007).

Tabela 2 - Índices de extremos climáticos baseados em dados de precipitação utilizados neste estudo.

\begin{tabular}{llc}
\hline \multicolumn{1}{c}{ Índices } & \multicolumn{1}{c}{ Definição } & Unidades \\
\hline Rx1day & Quantidade máxima de precipitação em um dia & $\mathrm{mm}$ \\
Rx5day & Quantidade máxima de precipitação em cinco dias & $\mathrm{mm}$ \\
RXnn & Número de dias acima de $X$ mm & Dias \\
R95p & Dias muito chuvosos & Dias \\
R99p & Dias extremamente chuvosos & Dias \\
DCC & Dias Consecutivos Chuvosos & Dias \\
DCS & Dias Consecutivos Secos & Dias \\
PRCPTOT & Precipitação Total Anual nos Dias Úmidos & $\mathrm{mm}$ \\
\hline
\end{tabular}

Fonte: Santos (2007).

\section{RESULTADOS E DISCUSSÕES}

Os anos de ocorrência do El Niño e de Dipolo do Atlântico estão apresentados na Tabela 3 e Tabela 4. As anomalias de temperatura da superfície do mar (atsm) indicam uma tendência positiva de aumento de temperaturas (Figura 2 a 5), com maior acentuação sobre 0 dipolo do Atlântico (Figura 5). As maiores anomalias de temperaturas foram de $6,3^{\circ} \mathrm{C}$ (Niño 3) e 5,240 C (Niño 3.4) nos anos de 1997 e 1982, respectivamente (Figuras 2 e 3). Ambos coerentes com a ocorrência de anos com El Niño forte, e também coerentes com a relação entre ocorrência do evento e anomalias negativas de chuva no NEB, destacadas por diversos autores. Sobre as regiões do dipolo do Atlântico Norte (DAN) e dipolo do Atlântico Sul (DAS), os maiores valores observados foram de 3,20 C em 1998 e 2,40 C em 2007, no Atlântico Norte. O ângulo de inclinação da reta de tendência foi mais acentuado sobre 0 Atlântico sul do que no norte.

Tabela 3 - Anos de ocorrência do ENOS.

\begin{tabular}{clc}
\hline & \multicolumn{1}{c}{ Ocorrências de El Niño } & \multicolumn{1}{c}{ Fraco } \\
\hline Forte & \multicolumn{1}{c}{ Moderado } & \multicolumn{1}{c}{ Fract } \\
$1957-1959 ; 1972-1973 ; 1982-$ & $1965-1966 ; 1968-1970 ;$ & $1951 ; 1953 ; 1963 ; 1976-1977 ;$ \\
$1983 ; 1990-1993 ; 1997-1998$ & $1986-1988 ; 1994-1995 ;$ & $1977-1978 ; 1979-1980 ; 2004-$ \\
& $2002-2003$ & $2005 ; 2006-2007 ; 2009-2010$ \\
\hline
\end{tabular}

Fonte: Oliveira et. al. (2010). 
Tabela 4 - Anos de ocorrência do Dipolo do Atlântico.

\begin{tabular}{cl}
\hline \multicolumn{1}{c}{ Fase Positiva } & \multicolumn{1}{c}{ Fase Negativa } \\
\hline $1951,1953,1954,1956,1958,1961,1970$, & $1950,1957,1959,1965,1967,1971,1972$, \\
$1976,1978,1981,1982,1990,1997,1998$, & $1973,1974,1975,1984,1986,1987,1989$, \\
2004,2007 & $1993,1994,1995,2001,2008$ \\
\hline
\end{tabular}

Fonte: Oliveira et. al. (2010).

O teste de Mann-Kendall evidenciou a tendência positiva com significância estatística para todas as áreas oceânicas estudadas. Sobre os Niños 3 e 3.4, o nível de significância foi de $5 \%$, já sobre o Atlântico Norte e Sul, nas quais a tendência foi mais acentuada, o nível de significância foi de $1 \%$. De fato, os resultados indicam que há tendência positiva sobre as temperaturas dos oceanos.

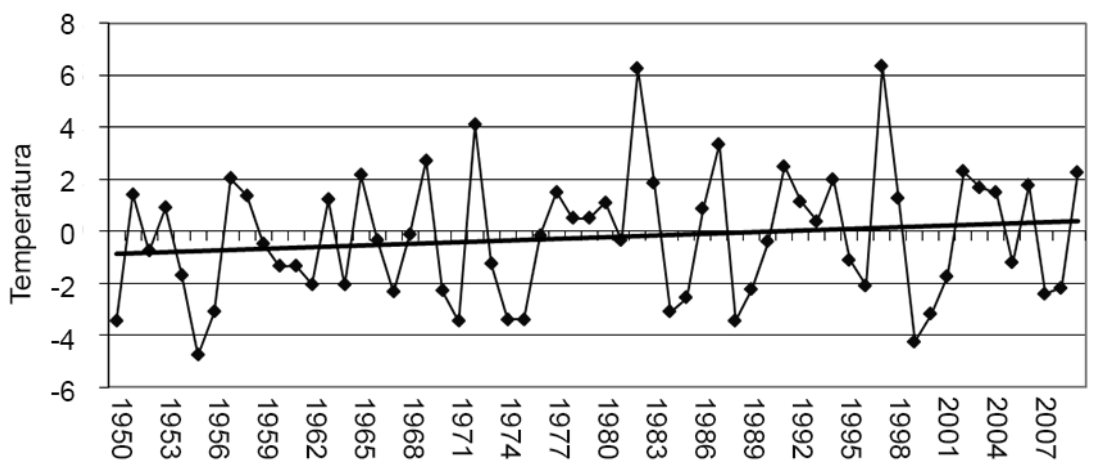

Figura 2 - Anomalias de temperatura sobre a superfície do mar na área do Niño 3 e reta de tendência linear. Fonte: Autores.

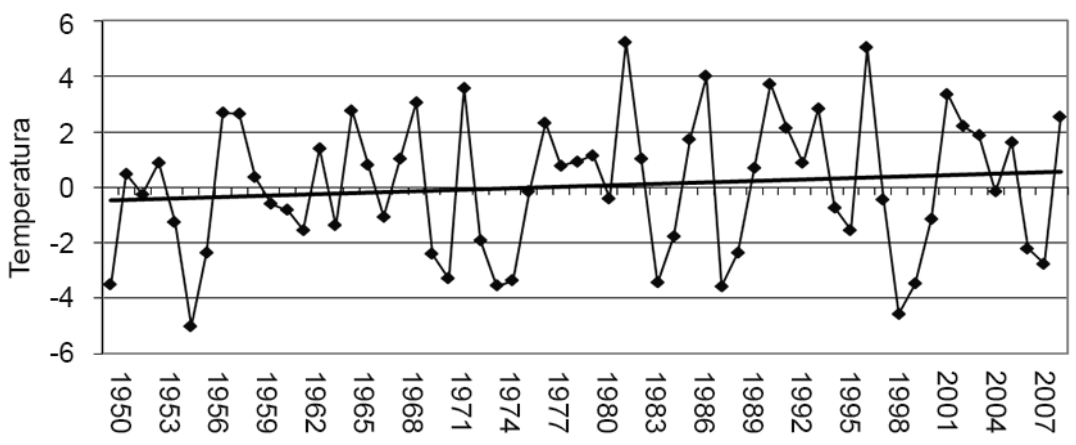

Figura 3 - Anomalias de temperatura sobre a superfície do mar na área Niño 3.4 e reta de tendência linear. Fonte: Autores. 


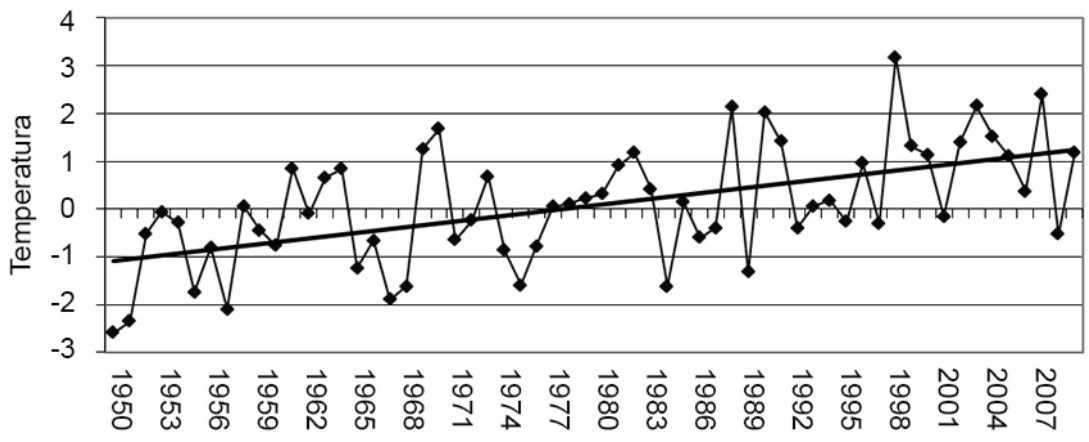

Figura 4 - Anomalias de temperatura sobre a superfície do mar na área do dipolo do Atlântico Norte e reta de tendência linear. Fonte: Autores.

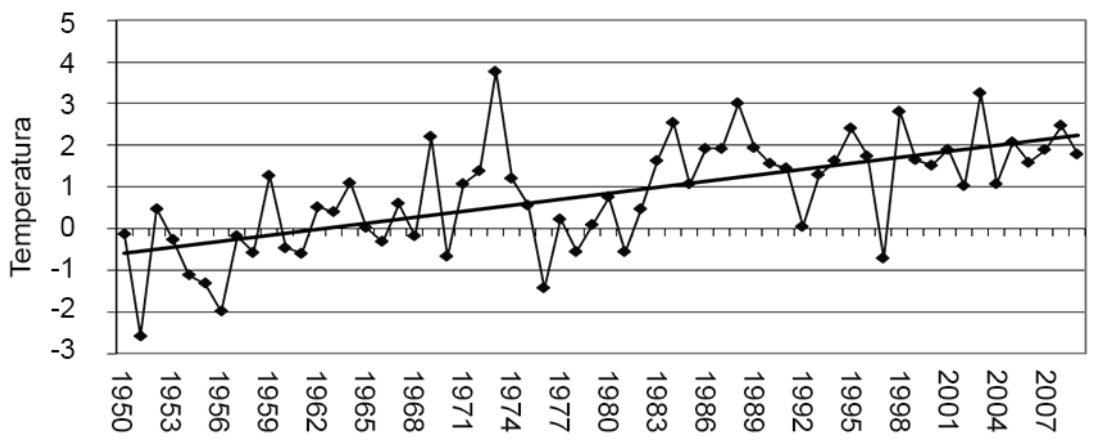

Figura 5 - Anomalias de temperatura sobre a superfície do mar na área do dipolo do Atlântico Sul e reta de tendência linear. Fonte: Autores.

A região de Recife, capital estadual, representa uma área com clima tropical chuvoso e vegetação do tipo Zona da Mata litorânea, possuindo o maior volume médio de precipitação das regiões estudadas. No IAC (Figura 6) observa-se que existe claramente o predomínio de anomalias negativas, ou seja, valores de precipitação abaixo do esperado entre 1951 a 1963. Neste período ocorrer apenas um El Niño classificado como forte, entre 1957 e 1959. Outros episódios que ocorreram no mesmo período foram classificados como fraco (1951, 1953 e 1963), porém dois destes episódios fracos atuaram em conjunto com a fase positiva do dipolo ocorrida em 1951 e 1953, resultando em IAC negativo, ou seja, anomalia de chuva negativa.

Nos anos seguintes, há predominância de IAC positivo até o 1981 . Nesse intervalo de anos ocorreu um El Niño forte e outros fracos, mesmo assim o IAC permaneceu positivo devido a atuação do dipolo negativo, incluindo entre os anos de 1972 e 1973. Outra grande seca foi em 1998, acompanhada de um dos mais intensos El Niño registrados. Além disso, neste ano, o fenômeno atuou em conjunto com a fase positiva do dipolo. A partir de 2000, há predominância de IAC positivo, e ausência de episódios de El Niño. 


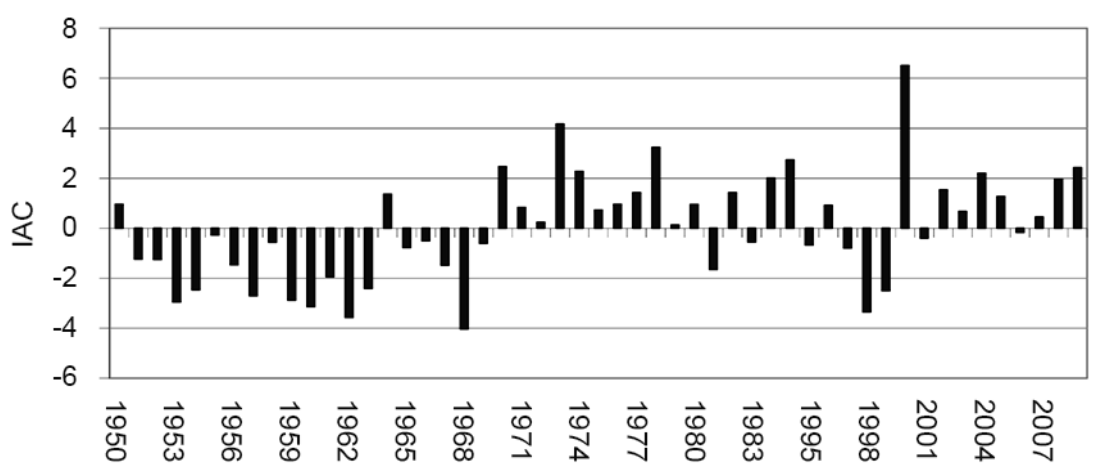

Figura 6 - Índice de anomalia de chuva para o município do Recife, PE. Fonte: Autores.

A região de Palmares, que também representa um clima tropical chuvoso, porém com volume de precipitação menor e sujeita a enchentes devido o relevo acidentado a montante e ocupação irregular ao redor dos canais fluviais. Percebe-se que há maior variabilidade entre períodos secos e chuvosos que em Recife (Figura 7). Também apresenta um período negativo entre 1952 e 1954, relacionado também com a ocorrência de El Niño fraco e a fase positiva do dipolo em 1953 e em 1957 a 1959, relacionado com ocorrência de El Niño de categoria forte em 57-59. Outro evento de anomalias negativas na precipitação foi em 1968, ano de ocorrência de El Niño moderado. Os valores extremos de anomalias negativas para a precipitação de Palmares foram em 1993 com 528 mm e 1998 com 504 mm acumulados em um ano. Estes episódios estiveram associados a ocorrência de El Niño de categoria forte e também a dipolo negativo. Mostrado assim a grande influência que esse evento exerce nesta localidade.

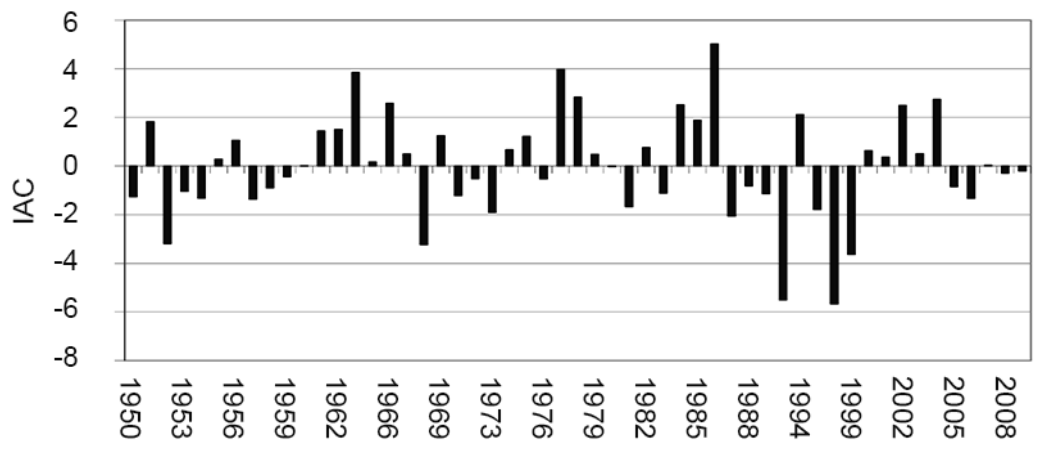

Figura 7 - Índice de anomalia de chuva para o município de Palmares, PE. Fonte: Autores.

Caruaru representa uma região de transição entre o clima tropical chuvoso e semiárido. Analisando o IAC (Figura 8) observa-se que o comportamento foi semelhante aos das regiões analisadas anteriormente, porém quando da ocorrência de anomalias, o IAC é mais expressivo quantitativamente. 


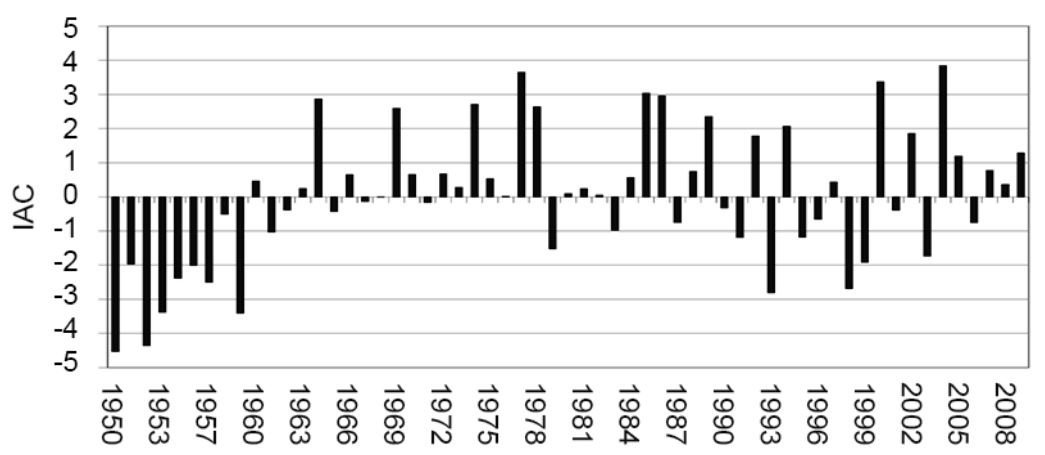

Figura 8 - Índice de anomalia de chuva para o município de Caruaru, PE. Fonte: Autores.

Serra Talhada representa o clima semiárido, com taxa de evapotranspiração acentuada, significativa variabilidade pluviométrica anual e vegetação hiperxerófila. Assim como nas outras regiões, Serra Talhada também teve seus níveis de precipitação (Figura 9) alterados pela ocorrência de El Niño e Fase positiva do dipolo do Atlântico, apresentando um longo período com chuvas abaixo da média em 1951 a 1960 neste mesmo período ocorreu em 1951 e 1953 El Niño fraco e fase positiva do dipolo, no entanto a situação mais extrema foi no ano de 1958 onde ocorreu El Niño Forte e Fase positiva do dipolo tendo sua média anual chegado aos $108 \mathrm{~mm}$, representando 16,9 \% da precipitação anual. Em 1965 ocorreu El Niño moderado que também causou chuvas abaixo na média no município, assim como em 1993 e 1998, com ocorrência de El Niño forte, que também alterou significativamente a chuva anual, com volume total de $288 \mathrm{~mm}$ e $216 \mathrm{~mm}$, respectivamente.

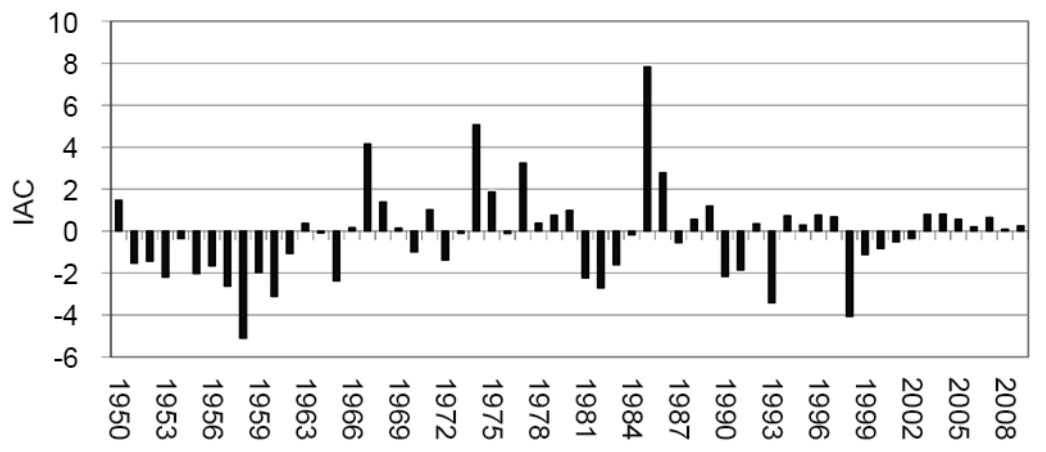

Figura 9 - Índice de anomalia de chuva para o município de Serra Talhada, PE. Fonte: Autores.

Uma vez evidenciado que as temperaturas sobre os oceanos possuem tendência de aquecimento e há relação entre as anomalias de temperaturas sobre os oceanos Pacífico e Atlântico e a precipitação, a seguir será analisado se há tendências na modificação da precipitação, através da análise de índices de mudanças climáticas.

As tendências dos índices de mudanças climáticas utilizados neste trabalho estão apresentadas na Tabela 5 . Os índices podem ser agrupados da seguinte maneira: os primeiros cinco índices (do Rx1dia até R99p) estão relacionados a eventos extremos; o DCC e DCS estão relacionados a distribuição sazonal; e o PRCPTOT a climatologia de precipitação anual.

Na tabela 5 são apresentados os valores dos índices. Os resultados mostram o sinal da tendência, bem como o seu nível de significância estatística, sendo que os valores em 
negrito correspondem às tendências com significância estatística ao nível de $5 \%(p \leq 0,05)$ e os demais valores correspondem às tendências com significância estatística ao nível de $10 \%$ $(p \leq 0,10)$. Na Região Metropolitana do Recife os resultados diferem dos demais pontos por apresentar tendência negativa em praticamente todos os índices (exceção do DCS). Este fato implica que há redução na precipitação, e alterações negativas na sua intensidade e distribuição sazonal, assim como, apresentou tendência de aumento nos dias consecutivos secos.

Para as demais regiões estudadas, há tendência significativa nos índices de eventos extremos, com destaque para a ocorrência de eventos extremos de precipitação (percentis 95 e 99). Com a tendência negativa dos dias consecutivos chuvosos, há mudanças na distribuição sazonal das chuvas, significando que as mesmas estão concentradas em menor período. Relacionando os índices entre si, os resultados convergem para chuvas mais irregulares, sobretudo nos locais onde já são.

A região de Serra Telhada está próxima do núcleo de desertificação de Cabrobó. Segundo Soares et al. (2011) desertificação é a degradação da terra de zonas áridas, semiáridas e subúmidas secas, resultante de vários fatores, incluindo as atividades humanas e as variações climáticas. A concentração das chuvas em menor período de tempo e com mais intensidade tende a intensificar o processo de desertificação, uma vez que o solo da região é raso e cristalino. Ao infiltrar e posteriormente infiltrar, há a transferência de sal de camadas inferiores do substrato do solo para a superfície, criando áreas de solo improdutivos até mesmo para a vegetação nativa, a caatinga.

Tabela 5 - Tendências dos índices de extremos de precipitação para os municípios estudados. Os valores em negrito correspondem às tendências com significância estatística ao nível de $5 \%(p \leq 0,05)$ (alta) e os demais valores correspondem às tendências com significância estatística ao nível de $10 \%(p \leq 0,10)$.

\begin{tabular}{lcccccccc}
\hline \multicolumn{1}{c}{ Região } & Rx1dia & Rx5dias & R50mm & R95p & R99p & DCC & DCS & PRCPTOT \\
\hline Recife & - & - & - & - & - & $\mathbf{0 , 6 7 5}$ & 0,238 & $-18,536$ \\
Palmares & $\mathbf{0 , 8 8}$ & $\mathbf{1 , 2 1}$ & $\mathbf{0 , 0 2}$ & $\mathbf{6 , 1 0}$ & $\mathbf{3 , 3 9}$ & $-\mathbf{0 , 3 0}$ & - & - \\
Caruaru & $\mathbf{0 , 8 9}$ & - & $\mathbf{0 , 0 3}$ & $\mathbf{7 , 7 2}$ & $\mathbf{5 , 2 4}$ & $-0,48$ & - & $\mathbf{1 0 , 7 1}$ \\
Serra Talhada & $\mathbf{0 , 6 4}$ & $\mathbf{0 , 7 5}$ & 0,02 & $\mathbf{6 , 0 5}$ & $\mathbf{2 , 5 2}$ & $\mathbf{- 0 , 2 9}$ & - & - \\
\hline
\end{tabular}

Fonte: Autores.

\section{CONCLUSÕES}

A análise estatística das TSM's sobre o oceano Pacífico e Atlântico permitiu observar que há tendência de aquecimento e que, quando analisados isoladamente a ocorrência de anomalias positivas sobre o Pacífico leste (El Niño) e anomalias negativas sobre o Atlântico Sul (dipolo positivo), as secas são mais severas, baseado na análise do índice de anomalia de chuva. Também baseado no IAC, conclui-se que ambos os eventos quando ocorrem isoladamente exercem influência na precipitação da região, no entanto, quando agem em conjunto percebesse que essa influência é mais acentuada, alterando o comportamento da circulação geral da atmosfera meridionalmente (célula de Hadley) e zonalmente (célula de Walker).

Os índices de mudanças climáticas indicaram que vem ocorrendo mudanças nos padrões de pluviometria, com tendência de aumento no volume de chuva (com exceção do litoral leste) e distribuição sazonal mais concentrada, de maneira que em uma região que já apresenta distribuição sazonal deste elemento climático entre dois a quatro meses, isto irá trazer graves impactos. 


\section{AGRADECIMENTOS}

Ao CNPQ pelo fomento ao projeto Peld Sercaatinga. A Propesq e à CAPES pela concessão de bolsas de pesquisa. Ao Grupo de Estudo Climatologia Tropical e Eventos Extremos (Tropoclima) da UFPE, pelo apoio à pesquisa. Também agradecemos ao Prof. Dr. Antônio Carlos de Barros Correa pelo auxílio nas correções do artigo.

\section{REFERÊNCIAS BIBLIOGRÁFICAS}

$A B$ 'SABER, A.N. Os domínios de natureza no Brasil: potencialidades paisagísticas. São Paulo: Atêlie Editorial, 2006.159 p.

ALLEY, W.M. The Palmer Drought Severity Index as a Measure of Hydrologic Drought. Water Resources Bulletin, 21, v. 1, 105-114, 1985.

ALLEY, W.M. The Palmer Drought Severity Index: Limitations and Assumptions. Journal of Climate and Applied Meteorology, v. 23, p.1100-1109, 1984.

ANDRADE, M.C. A Terra e o Homem no Nordeste. 7 ed. São Paulo, Cortez Editora, 2005.

ANDREOLI, R.V. et al. A Influência da Temperatura da Superfície do Mar dos Oceanos Pacífico e Atlântico na Variabilidade de Precipitação em Fortaleza. Revista Brasileira de Meteorologia, v.19, n.2, p.113-122, 2004.

ANDREOLI, R.V.; KAYANO, M.T. A importância relativa do Atlântico Tropical Sul e Pacífico Leste na variabilidade de precipitação do Nordeste do Brasil. Revista Brasileira de Meteorologia, v. 22, n.1, p.63-74, 2007.

ARAGÃO, J.O. R. O Impacto do ENSO e do Dipolo do Atlântico no Nordeste do Brasil. Bull Inst. Fr. Études Andines, v.27, n.3, p.839-844, 1998.

ASSAD, E.; PINTO, H. S. Aquecimento global e a nova geografia da produção agrícola no Brasil. In: DECONTO, J. G. (Coord.). Aquecimento global e a nova geografia da produção agrícola no Brasil. São Paulo: Embrapa Agropecuária: Unicamp, 2008. 83p. Disponível em: <http://www.agritempo.gov.br/climaeagricultura/download.html>. Acesso em: agosto de 2013.

BEZERRA, A.C.N.; CAVALCANTI, E.P. Energia estática sobre o norte e Nordeste do Brasil relacionada com a temperatura da superfície do mar. Revista Brasileira de Meteorologia, v.23, n.2, p.239-263, 2008.

CARVALHO, O.D.; EGLER, C.A.G. Alternativas de Desenvolvimento para o Nordeste Semi-árido, Banco do Nordeste, Fortaleza.

DA SILVA, D. F.; GALVINCIO, J.D.; NÓBREGA R.S. Influência da variabilidade climática e da associação de fenômenos climáticos sobre sub-bacias do rio São Francisco. Revista Brasileira de Ciências Ambientais, n. 19, 2011.

ENFIELD, D.B.; MESTAS-NUÑEZ, A.M.; MAYER, D.A.; CID-SERRANO, L. How ubiquitous is the dipole relationship in tropical Atlantic sea surface temperature? J. Geophys. Res., v.104, n.C4, p.78417848, 1999.

GOMES, G. M. Velhas Secas em Novos Sertões: Continuidade e Mudanças na Economia do Semiárido e dos Cerrados Nordestinos. Brasília, IPEA, 2001.

GOOSSENS, C.; BERGER, A. Annual and seasonal climatic variations over the northern hemisphere and Europe during the last century. Annales Geophysicae, Berlin, v.4, p.385-400, 1986. 
GROPPO, J.D. et. al. Análise de Séries Temporais de Vazão e de Precipitação na Bacia do Rio Piracicaba. Revista de Ciência e Tecnologia, v.8, n.18, p.109-117, 2001.

GUANZIROLI, C.E., CARDiM, S. E. C. S. Novo Retrato da Agricultura Familiar-O Brasil Redescoberto. Projeto de Cooperação Técnica. Brasília, INCRA (Instituto Nacional de Colonização e Reforma Agrária), FAO (Food and Agriculture Organization), 2000.

GUTTMAN, N.B.A Sensitivity Analysis of the Palmer Hydrologic Drought Index. Water Resources Bulletin, v. 27, n. 5, p.797-807, 1991.

HANSEN, J.E., R. et al. A closer look at United States and global surface temperature change. J. Geophys. Res., 106, 23947-23963. 2001. doi:10.1029/2001JD000354.

HASTENRATH, S.; HELLER, L. Dynamics of climatic hazards in Northeast Brazil. Quartely Journal Royal Meteorological Society, v.103, n.435, p.77-92, 1977.

HAVENS, A.V. Economic Impact of Drought on Water Systems in Passaic River Basin, Journal New Brunswick, New Jersey Agricultural Experiment Station, 1969.

IBGE -Instituto Brasileiro de Geografia e Estatística. Censo Demográfico 2010, 2010. Disponível em < ftp://ftp.ibge.gov.br/Censos/Censo_Demografico_2010/ >.

IPCC - Intergovernmental Panel on Climate Change. Twelfth Session of Working Group I. Summary for Policymakers, 2013. Disponível em: < http:// www.climatechange2013. org/images/uploads/WGIAR5-SPM_Approved27Sep 2013 .pdf>.

KANE, R. P. Prediction of droughts in North-east Brazil: Role of ENSO and use of periodicities. Inter. J. Climatol.,v.17, p.655-665, 1997.

KAYANO, M.T.; CAPISTRANO, V.B. How the Atlantic multidecadal oscillation (AMO) modifies the ENSO influence on the South American rainfall. International Journal of Climatology, v. n/a, p. n/a-n/a, 2013.

KLAUER, A. El Niño - La Niña: El Fenómeno oceano-atmosférico Del Pacífico Sur, um reto para La ciência y La historia. 1a. Ed. Agosto.76 págs. 2000.

KOBIYAMA, M.; MOTA, A.A.; GRISON, F.; GIGLIO, J.N. Landslide influence on turbidity and total solids in Cubatão do Norte River, Santa Catarina, Brazil. Natural Hazards, v.59, n.2, p.1077-1086, 2011.

MALUF, R.S., BURLANDY, L. Power, Inequality and Social Policies in Brazil. Working papers 1, CERESAN, Rio de Janeiro, 2007.

MARENGO, J.A. Água e mudanças climáticas. Estudos Avançados, v. 22, p. 83-96, 2008.

MARENGO, J. A., AMBRIZZI, T., ROCHA, R. P., et al. Future change of climate in South America in the late twenty-first century: intercomparison of scenarios from three regional climate models. Climate Dynamics, sem volume, 2009.

MARENGO, J., DRUYAN, L., HASTENRATH, S. Observational and modelling studies of Amazonia interannual climate variability. Climatic Change, v. 23, n.3, p.267-286, 1993.

MARGULIS, S., DUBEUX, C. B. S. Economia da Mudança do Clima no Brasil: Custos e Oportunidades. São Paulo, IBEP Gráfica, 2010.

MELO, J.C. O Fenômeno EI Niño e as Secas no Nordeste do Brasil. In: Raízes, ano XVIII, n.20, 1999.

MOURA, A.D.; SHUKLA, J. On the dynamics of droughts in northeast Brazil: Observations, theory and numerical experiments with a general circulation model. J. Atmos. Sci., 38, p.2653-2675, 1981. 
NOBRE, P.; SHUKLA, J. Variations of sea surface temperature, wind stress, and rainfall over the tropical Atlantic and South America. Journal of Climate, v. 9, n.10, p.2464-2479, 1996.

OBERMAIER, M. Brazil's Public Policy Package for Successful Farmer Adaptation. ELLA (Evidence and Lessons from Latin America) Policy Brief, Practical Action, DFID, Lima, 2012. Disponível em: <http://ella.practicalaction.org/>.

OLIVEIRA, G.C.S; ALVES, K.M.A.S.; NÓBREGA, R.S. Sistemas Atmosféricos Dinâmicos de Grande Escala Responsáveis pela Ocorrência de Chuva no Nordeste Brasileiro. In: II Workshop de Mudanças Climáticas e Recursos Hídricos de Pernambuco, 2010, Recife. Mudanças Climáticas e Recursos Hídricos. Recife, 2010.

QUINN, F. Hydrologic response model of the North American Great Lakes. Journal of Hydrology, v.37, p.295-307, 1978.

SANTOS, C.A.C; BRITO, J.I.B. Analysis of indices of extremes for the semi-arid of Brazil and its relations with SST and NDVI. Rev. Bras. Meteorol., vol.22, n.3, pp. 303-312, 2007.

SERVAIN, J. Simple Climatic Indices for the Tropical Atlantic Ocean and some Applications. Journal of Geophysical Research, v.96, p. 15.137-15.146, 1991.

SILVA, R.M.A. Entre o combate à seca e a convivência com o semi-árido: políticas públicas e transição paradigmática, Revista Econômica do Nordeste, v. 38, pp. 466-485, 2007.

SilVeirA, F. G., CARVALHO, X. X. Y., AZZONI, C. R., et al. Dimensão, Magnitude e Localização das Populações Pobres no Brasil. Texto para discussão 1278, IPEA, Brasília, 2007.

SOARES, D.B.; MOTA FIHO, F.O.; NÓBREGA, R.S. Sobre o processo de desertificação. Revista Brasileira de Geografia Física, vol. 01, 174-188, 2011.

STEILA, D. Drought Analysis in Four Southern States by a New Index. PhD Diss., Athens, Ga., The University of Georgia, 1971.

XAVIER, T. DE MA. B. S.; XAVIER, A. F. S. O Planeta Terra: Aquecimento Global e Mudanças Climáticas. BSBMET, v.30, n.4, p.73-79, 2007.

ZHANG, X.; HARVEY, K.D.; HOGG, W.D.; YUZYK, T.R. Trends in Canadian stream flow. Water Resources Research, v.37, n.4, p.987-998, 2001. 